\title{
Study on Pricing Strategy of Hybrid Distribution Channels of Cruise Companies
}

\author{
Yang Yang \\ School of Economics \& Management \\ Chongqing Normal University \\ Chongqing, China \\ 784140182@qq.com
}

\author{
Huashan Tan \\ College of Computer and Information Science \\ Chongqing Normal University \\ Chongqing, China \\ 6510388@qq.com
}

\begin{abstract}
With the development of E-commerce, many cruise companies reconstruct their distribution channels by adding the electronic direct marketing system. This paper researches the product pricing problems of cruise companies based on hybrid distribution channels, discusses a manufacture-leader Stackberg game model and a Bertrand game model, and gives equilibrium results of pricing game between cruise companies and distributors. By comparing the equilibrium prices and the profit gains using the different pricing strategies, the most superior pricing strategies under different wholesale price range are proposed.
\end{abstract}

Keywords- product pricing; game theory; Nash equilibrium; hybrid distribution channels; Stackberg game

\section{INTRODUCTION}

The cruise company in ticket sales has been using the distribution channel management in the past. But with the development of E-commerce and network technology, many cruise companies built up their own electronic distribution channel. Comparing the traditional distribution channels, the electronic distribution channel has many advantages such as distance-destroying, reducing intermediate links, low transaction costs etc., so more and more cruise companies reconstruct their distribution channels by adding the electronic distribution channel. They are called hybrid distribution channels. In the supply chain based on hybrid distribution channels, there is a mix of competition and cooperation between producers and distributors. Encouragement and competition between them have become hot topics among scholars and researches around the world, but there are most of studies on this problem in the traditional distribution channels [12]. Study on the hybrid distribution channels is not sufficient. In the existing literature, Netessine \& Rudi discuss the supply chain choice of producers from an inventory risk standpoint [3]. Chiang \& Monahan research that the producers use electronic sales channel to sell the remaining product, and drew a conclusion that it can reduce the cost of distribution significantly in the hybrid distribution channels [4]. Dumrongsiri makes a supply chain model with direct and retail channels. It has no clear conclusion on pricing, coordination and incentive in hybrid distribution channels. The cruise company's pricing decision will not only affect the other distributor's demand, but their own demand will be also affected by the other distributors. So it is meaningful to study pricing strategy of hybrid distribution channels [5].

This paper uses the game theory to research the product pricing problems of cruise companies in the hybrid distribution channels. There is a producer, namely a cruise company, and a distributor in the hybrid distribution system (see Fig 1). Their own interests between the cruise company and the distributor are often served through pricing strategy. Considering a Stackberg game model and a Bertrand game model, this paper uses multivariate linear regression model to deduce the empirical relation between sale quantity and prices of the cruise company and the distributor, and gives equilibrium results of pricing game. By comparing the equilibrium prices and the profit gains using the different pricing strategies, the most superior pricing strategies under different wholesale price rang are proposed.

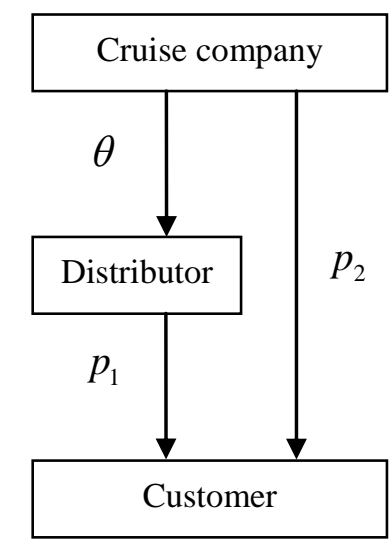

Figure 1. distribution channels structure

\section{THE GAME MOdEl BeTWEen CRUISE COMPANY AND DISTRIBUTOR}

\section{A. The model assumptions and parameters}

The demand of the commodity and the service is influenced by many factors, such as prices, consumer's income, prices of related goods, consumer preference. This paper mainly researches the relationship between the quantity demanded and the price. It assumes that the cruise company and the distributor are rational, and the information between them is symmetry.

Description of variables and parameters is as follows: 
The ticket sales price of the traditional distribution channel is denoted by parameter, while the price of the electronic distribution channel is denoted by parameter. The parameter says the ticket wholesale price between them. In order to put the focus on the ticket pricing strategy between the cruise company and the distributor, it makes a hypothesis that the variable is exogenous, which is determined by the market [6].

The distributor's demand function is as follows:

$$
q_{1}=a_{1}-b_{1} p_{1}-\theta\left(p_{1}-p_{2}\right)
$$

While the cruise company's demand function is as follows:

$$
q_{2}=\theta\left(p_{1}-p_{2}\right)
$$

In these equations, all the parameters are greater than zero, and the inequality is true. If the inequality is false, the distributor which buys tickets from the electronic channel directly can earn more profit, it does not accord with common sense. The parameter says the saturation of the market demand for tickets, the parameter says the price elasticity of demand from the distribution channel, and the parameter says the price elasticity of demand from the price variance between the two different channels. The model parameters can be obtained from historical data through the statistical analysis.

The profit function of the distributor is as follows:

$$
\begin{aligned}
R_{1} & =\left(p_{1}-\omega\right) q_{1} \\
& =\left(p_{1}-\omega\right)\left[a_{1}-b_{1} p_{1}-\theta\left(p_{1}-p_{2}\right)\right]
\end{aligned}
$$

The profit function of the cruise company is as follows:

$$
\begin{aligned}
R_{2} & =\omega q_{1}+p_{2} q_{2} \\
& =\omega\left[a_{1}-b_{1} p_{1}-\theta\left(p_{1}-p_{2}\right)\right]+p_{2} \theta\left(p_{1}-p_{2}\right)
\end{aligned}
$$

The overall profit function of supply chain is as follows:

$$
R=R_{1}+R_{2}
$$

The cruise company and the distributor make pricing strategy based on the revenue maximization principle. The decision model is the equation:

$$
\max R=p q=p(a-b p)
$$

\section{B. A manufacture-leader Stackberg game model}

The distributor develops their own price according to the price of the electronic distribution channels. Therefore a manufacture-leader Stackberg game model can be built. In order to achieve profit maximization, the cruise company will choose the price. According to this price, the distributor can set their own price to maximize their profit. But the model is solved in reverse order.

The distributor makes the optimal pricing strategy firstly. By the optimization fist-order condition, the model solution is as follows:

$$
\frac{\partial R_{1}}{\partial P_{1}}=0
$$

We can get solution as follows:

$$
p_{1}^{S}=\frac{a_{1}+\theta p_{2}+\left(b_{1}+\theta\right) \omega}{2\left(b_{1}+\theta\right)}
$$

If we put the variable $p_{1}^{S}$ into the equation (4), we can get the profit function $R_{2}=R\left(p_{2}\right)$. Letting $\frac{\partial R_{2}}{\partial P_{2}}=0$, so we can get the optimal price of the cruise company as follows:

$$
p_{2}^{S}=\frac{b_{1} \omega+\theta \omega+a_{1} / 2}{2\left(b_{1}+\theta\right)}
$$

If we put the variable $p_{2}^{S}$ into the equation (7), we can get the optimal price of the cruise company as follows:

$$
\begin{aligned}
p_{1}^{S} & =\frac{a_{1}+\theta p_{2}^{S}+\left(b_{1}+\theta\right) \omega}{2\left(b_{1}+\theta\right)} \\
& =\frac{\omega}{2}+\frac{1}{2\left(b_{1}+\theta\right)\left(2 b_{1}+\theta\right)}\left(2 a_{1} b_{1}+\frac{3}{2} a_{1} \theta+b_{1} \omega \theta+\omega \theta^{2}\right)
\end{aligned}
$$

From it, we can get the only Nash equilibrium solution as follows:

$\left\{\begin{array}{l}p_{1}^{S}=\frac{\omega}{2}+\frac{1}{2\left(b_{1}+\theta\right)\left(2 b_{1}+\theta\right)}\left(2 a_{1} b_{1}+\frac{3}{2} a_{1} \theta+b_{1} \omega \theta+\omega \theta^{2}\right) \\ p_{2}^{S}=\frac{b_{1} \omega+\theta \omega+a_{1} / 2}{2\left(b_{1}+\theta\right)}\end{array}\right.$

\section{A Bertrand game model}

By hypothesis, we can build the static game model on complete information. In this situation, the distributor does not consider the price of electronic distribution channel. This is a typical Bertrand game model [7]. It's an uncooperative game model. At this time, both sides consider their pricing strategy. Their target is maximization of their own profits. The optimization mode is as follows:

$$
\left\{\begin{array}{l}
\frac{\partial R_{1}}{\partial P_{1}}=a_{1}-2 b_{1} p_{1}-2 \theta p_{1}+\theta p_{2}+\omega b_{1}+\omega \theta=0 \\
\frac{\partial R_{2}}{\partial P_{2}}=\omega \theta+\theta p_{1}-2 \theta p_{2}=0
\end{array}\right.
$$
follows

The optimal response strategy of the distributor is as

$$
p_{1}^{B}=\frac{a_{1}+\theta p_{2}^{B}+\left(b_{1}+\theta\right) \omega}{2\left(b_{1}+\theta\right)}
$$


The optimal response strategy of the cruise company is as follows:

$$
p_{2}^{B}=\frac{\omega+p_{1}^{B}}{2}
$$

From equation (12) and equation (13), we can get the only Nash equilibrium solution as follows:

$$
\left\{\begin{array}{l}
p_{1}^{b}=\frac{2\left(a_{1}+b_{1}\right)+3 \omega \theta}{4 b_{1}+3 \theta} \\
p_{2}^{b}=\frac{a_{1}+b_{1}+\omega\left(2 b_{1}+3 \theta\right)}{4 b_{1}+3 \theta}
\end{array}\right.
$$

From the equilibrium price, we can draw a conclusion that the equilibrium price is influenced by the wholesale price. And then it can influence the profit function and the pricing decision of both sides. So we should make a sensitivity analysis about the variable $\omega$. But there are many parameters in two game models, the best choice is to make a numerical analysis [8-10].

Further, we can obtain the enlightenment on management that the efficiency of the decision under the different wholesale price. From the angle of the efficiency, both sides have the potential incentive to select the optimal pricing strategy.

\section{AN EXAMPLE OF MODEL AND SOLUTION}

Now we discuss a specific example. The Table I below is the ticket sales data of Chongqing Yangtze River Cruise Company and Sunshine international travel agency (the distributor) in some years in an area.

TABLE I. TICKET SALES DATA OF Two COMPANIES

\begin{tabular}{|c|c|c|c|c|c|c|c|}
\hline VAR & Apr & May & Jun & Jul & Aug & Sep & Oct \\
\hline$p_{2}$ & 4250 & 4150 & 4200 & 4200 & 4300 & 4500 & 4200 \\
\hline$q_{2}$ & 6037 & 3675 & 4203 & 6405 & 7350 & 7875 & 4211 \\
\hline$p_{1}$ & 4800 & 4500 & 4600 & 4700 & 5000 & 5200 & 4600 \\
\hline$q_{1}$ & 12079 & 15575 & 14712 & 11831 & 10154 & 8753 & 14535 \\
\hline
\end{tabular}

$p_{2}$ : Ticket price of Chongqing Yangtze River cruise company (unit: RMB Yuan).

$q_{2}$ : Sales volume of Chongqing Yangtze River Cruise Company.

$p_{1}$ : Ticket price of Sunshine international travel agency (unit: RMB Yuan).

$q_{1}$ : Sales volume of Sunshine international travel agency.
Using the data in Table I by the regression output results of SPSS software, it can be obtained the multivariate linear regression model of the empirical relation between sales volume and prices of the two companies as follows:

$$
\begin{aligned}
& q_{1}=35676.034-3.611 p_{1}-11.059\left(p_{1}-p_{2}\right) \\
& T=(2.200) \quad(-1.533) \quad(-0.883) \\
& \text { Sig }=(0.93) \quad(0.200) \quad(0.427) \\
& R=0.978 \quad R^{2}=0.956 \quad F=43.651
\end{aligned}
$$

$$
q_{2}=11.059\left(p_{1}-p_{2}\right)
$$

After we get the parameters of the multiple linear regression model, we also need to make the statistical test of the regression function fatherly. At the first, we make the $\mathrm{T}$ test for the regression coefficients of the formula (15). From the $\mathrm{T}$ test results we can see that prices of the two companies have the significant effect on the sales volume. Then, the F test was performed on the overall significance of the regression model.

So we can get values of these parameters as follows:

$$
a_{1}=35676, b_{1}=3.66, \theta=11
$$

In order to further study, the maximum profit of distributor expressed by variable $R_{1}^{S}$ and the maximum profit of cruise company expressed by variable $R_{2}^{S}$ when the Stackberg game model was selected. On the other side, variable $R_{1}^{B}$ shows the maximum profit of distributor and variable $R_{2}^{B}$ shows the maximum profit of the cruise company when the Bertrand game model was selected. Then we get economic sensitivity analysis results about the wholesale price (see Table II and Table III).

TABLE II. PROFIT OF SUNSHINE INTERNATIONAL TRAVEL AGENCY

\begin{tabular}{|c|c|c|c|c|c|}
\hline$\omega$ & $p_{1}^{B}$ & $p_{1}^{S}$ & $R_{1}^{B}$ & $R_{1}^{S}$ & $R_{1}$ \\
\hline 3500 & 4334.61 & 4943.01 & 16698033 & 15717483 & 15231000 \\
\hline 3700 & 4414.63 & 5023.03 & 14226190 & 14023172 & 13129500 \\
\hline 3800 & 4014.52 & 4622.92 & 6187936 & 9927467 & 11769600 \\
\hline 3900 & 4094.54 & 4702.94 & 5586621 & 9451291 & 9464800 \\
\hline 4000 & 4174.56 & 4782.97 & 4990500 & 8986817 & 9663200 \\
\hline 4100 & 4254.59 & 4862.99 & 4399574 & 8534046 & 6230000 \\
\hline
\end{tabular}


TABLE III. PROFIT OF CHONGQING YANGTSE RIVER CRUISE COMPANY

\begin{tabular}{|c|c|c|c|c|c|}
\hline$\omega$ & $p_{2}^{B}$ & $p_{2}^{S}$ & $R_{2}^{B}$ & $R_{1}^{S}$ & $R_{2}$ \\
\hline 3500 & 4303.6 & 4407.21 & 69325499 & 67131594 & 68649000 \\
\hline 3700 & 4388.24 & 4476.48 & 72048778 & 68761909 & 67036100 \\
\hline 3800 & 3965.06 & 4130.13 & 78426682 & 72708858 & 74385600 \\
\hline 3900 & 4049.7 & 4199.4 & 79440701 & 73308533 & 69240900 \\
\hline 4000 & 4134.33 & 4268.67 & 80409209 & 73849631 & 74028500 \\
\hline 4100 & 4218.97 & 4337.94 & 81332206 & 74332154 & 79835000 \\
\hline
\end{tabular}

In order to compare, we can see changes of profit in the different pricing strategies (see Fig 2 and Fig 3).

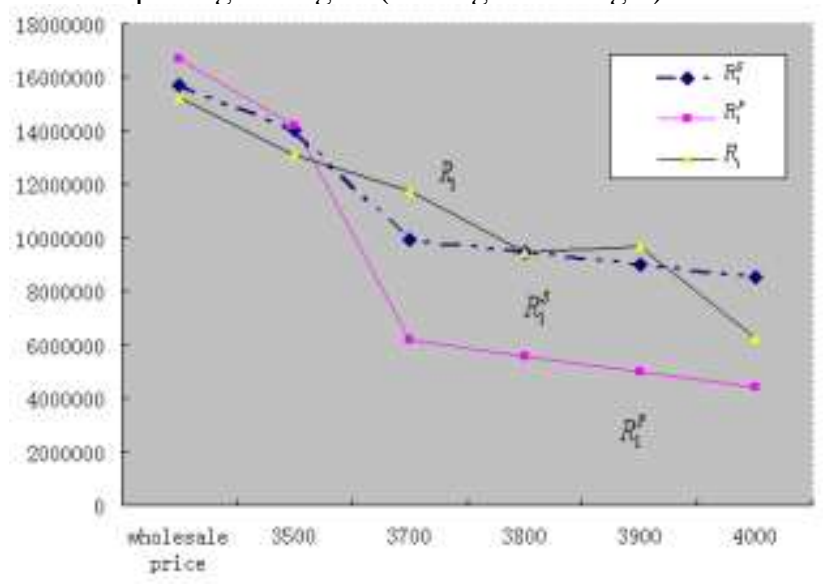

Figure 2. Profit comparison of Sunshine international travel agency in the different pricing strategies

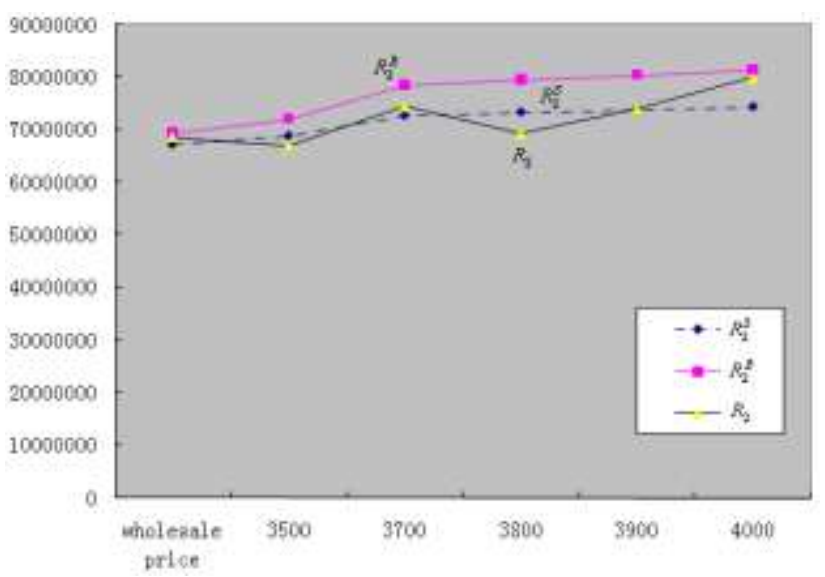

Figure 3. Profit comparison of Chongqing Yangtse River Cruise Company in the different pricing strategies

In the price game between the cruise company and the distributor, the cruise company is dominant. It will choose the most advantageous pricing strategy. The equilibrium solution under the Bertrand game model is the best choice.
For distributor, the pricing strategy is greatly affected by the wholesale price. When the wholesale price is less than 3500 , the equilibrium price under the Bertrand game model is the best choice. When the wholesale price is greater than 3900, the equilibrium price under the Stackberg game model is the best choice.

\section{CONCLUSIONS}

This paper uses the game theory to discuss the product pricing strategy when the electronic distribution channel is added into the traditional distribution system. The pricing strategy under manufacturer-leader Stackberg game model and the Bertrand game mode are discussed. Based on the profit comparison of two different equilibrium prices, we can draw a conclusion that the pricing strategy is influenced by the wholesale price. The optimal pricing strategy is got through the sensitivity analysis. This research is based on hypothesis of information symmetry. If the information is asymmetric, the further study on the pricing strategy between the cruise company and the distributor will be required.

\section{ACKNOWLEDGMENT}

This work was supported by the Science Technology Researching Fund of Chongqing Education Committee (KJ100623, KJ110629).

\section{REFERENCES}

[1] Chen K Y, Kaya M and Ozer O, Dual sales channel management with service competition, Manufacturing \& Service Operations Management, 2008, 10(4):654-675.

[2] Berstein F, Federgruen A, Pricing and replenishment strategies in distribution system with competing retailers, Operations Research, 2003, 51(3): 409-426.

[3] Netessin S, Rudi N, Supply chain choice on the internet Management Science, 2006, 52(6):844 -864

[4] Chiang W K, Monahan G E, Managing inventories in a twoechelon dual-channel supply chain, European Journal of Operation Research, 2005, 162(2):325 -341.

[5] Dumrongsiri A, Fan M, Jain A and Moinzadeh K, A supply chain model with direct and retail channels, European Journal of Operation Research, 2008, 187(3):691 -718.

[6] Huang W, Swaminathan J M, Introduction of a second channel Implications for pricing and profits, European Journal of Operation Research, 2009, 194(1):258 -279.

[7] Sun X, Gauri D K, Webster S, Forecasting for cruise line revenue management, Journal of Revenue \& Pricing Management, 2011 10(4):306-324.

[8] Sun X, Jiao Y, Tian $\mathrm{P}$, Marketing research and revenue optimization for the cruise industry: A concise review, international Journal of Hospitality Management, 2011, 30(3):746755.

[9] Ji L, Mazzarella J, Application of modified nested and dynamic class allocation models for cruise line revenue management, Journal of Revenue \& Pricing Management , 2007, 6(1):19-32.

[10] Kwon C, Friesz T L, Mookherjee R, et al. Non-cooperative competition among revenue maximizing service providers with demand learning. European Journal of Operational Research, 2009 197(3):981-996. 